mobile. While there is considerable time and route variation in air pollutant measurement, the levels of air pollutants measured in this study may have serious health implications for those who perform physically demanding activities near or on roadways in the City of Chicago.

\section{QUANTIFYING HAZARDOUS OCCUPATIONAL EXPOSURES AND INJURIES IN HOME CARE: RESULTS FROM THE SAFE HOME CARE SURVEY}

${ }^{1}$ Margaret Quinn, 'Pia Markkanen, 'Catherine Galligan, 'Susan Sama, 'David Kriebel, ${ }^{1}$ Rebecca Gore, 'Laura Punnett, ${ }^{2}$ Letitia Davis, ${ }^{2}$ Angela Laramie, 'Natalie Brouillette, ${ }^{1}$ Daniel Okyere, ${ }^{1}$ Chuan Sun. ${ }^{1}$ University of Massachusetts Lowell, Lowell, MA, USA; ${ }^{2}$ Massachusetts Department of Public Health, Boston, MA, USA

10.1136/oemed-2014-102362.120

Objectives In countries with ageing populations, home care (HC) aides are among the fastest growing jobs. There are few quantitative studies of $\mathrm{HC}$ occupational safety and health (OSH) hazards. The objectives of this study were to quantify a range of $\mathrm{OSH}$ exposures and injuries among $\mathrm{HC}$ aides and to evaluate the variability across job categories.

Method HC aides were recruited for a survey via agencies that employ aides and schedule their visits with clients and through a labour union of aides employed directly by clients/families. The innovative questionnaire design included detailed questions about the most recent home visits, as well as about the individual aides' OSH experiences.

Results The final population included 1249 HC aides (634 agency-employed, 615 client-employed) contributing information on $3484 \mathrm{HC}$ visits. Among aides, in the past 12 months, 2\% had a needlestick or other sharps injury; $7 \%$ reported physical aggression and 19\% verbal aggression; $11 \%$ had a job-related injury resulting in lost work time or need for medical care; 33\% reported back pain: of these, $59 \%$ experienced pain once a week or more and $68 \%$ took medication for it. Among visits, in the past month, $62 \%$ involved patient handling while only $25 \%$ involved a patient handling device; $80 \%$ involved cleaning, $10 \%$ indoor cigarette smoke. Agency-employed versus client-employed aides differed by amount of client handling, use of sharps, and characteristics of clients.

Conclusions Aides experience substantial OSH exposures and injuries. Quantification of hazards is useful to prioritise resources for the development of preventive interventions and to provide a foundation for etiologic research.

\section{EVALUATION OF CUMULATIVE EXPOSURE TO CARBON BLACK AND LUNG CANCER RISK AMONG US CARBON BLACK WORKERS}

'Linda Dell, ${ }^{1}$ Alexa Gallagher, ${ }^{1}$ Lori Crawford, ${ }^{2}$ Rachael Jones, ${ }^{1}$ Kenneth Mundt. ${ }^{1}$ ENVIRON International Corp., Amherst, MA, USA; ${ }^{2}$ University of Illinois at Chicago, Chicago, IL, USA

\subsection{6/oemed-2014-102362.121}

Objectives To evaluate lung cancer mortality in relation to quantitative estimates of cumulative inhalable carbon black exposure among carbon black manufacturing workers.

Method Standardised mortality ratios (SMRs) were calculated for 5675 workers employed $\geq 1$ year since 1940 at 18 plants. Cox proportional hazards models were used to evaluate the association between cumulative inhalable carbon black exposure and lung cancer mortality risk for the "exposure" sub-cohort of 2099 men with complete work history records that allowed individual quantitative estimation of cumulative exposure.

Results All-cause $\mathrm{SMR}=0.80 \quad(95 \%$ confidence interval [CI] $=0.76-0.84)$, all-cancer $\mathrm{SMR}=0.80(95 \% \mathrm{CI}=0.73-0.88)$ and lung cancer mortality $\mathrm{SMR}=0.80(95 \% \mathrm{CI}=0.68-0.94)$ showed significant deficits. In the exposure sub-cohort, lung cancer mortality was not increased $(\mathrm{SMR}=0.68,95 \% \mathrm{CI}=0.44-1.00, \mathrm{n}=$ 20). Time-dependent Cox analyses of the exposure sub-cohort showed no positive associations: Hazards Ratio $[\mathrm{HR}]=0.20$ $(95 \% \mathrm{CI}=0.04-0.9)$ for 20 to $<50 \mathrm{mg} / \mathrm{m}^{3}$-years; $\mathrm{HR}=0.7(95 \%$ $\mathrm{CI}=0.20-2.0)$ for 50 to $<99 \mathrm{mg} / \mathrm{m}^{3}$-years; and $\mathrm{HR}=0.5(95 \%$ $\mathrm{CI}=0.1-1.7)$ for $\geq 100 \mathrm{mg} / \mathrm{m}^{3}$-years, compared with those with $<20 \mathrm{mg} / \mathrm{m}^{3}$-years.

Conclusions No excess lung cancer mortality or association between lung cancer mortality and time-dependent cumulative inhalable carbon black exposure were observed. However, few lung cancer deaths occurred among the exposure sub-cohort. Nevertheless, lung cancer mortality among the older, full cohort also was not increased using duration of employment as a surrogate of cumulative carbon black exposure.

\section{NEUROLOGIC AND REPRODUCTIVE EFFECTS OF SOLVENTS ON AUTOMOTIVE REPAIR WORKERS: ASSESSMENT OF EXPOSURE FOR THE BAY AREA SOLVENT STUDY (BASS)}

Katharine Hammond, Sa Liu, Sophie Horiuchi. University of California, Berkeley, Berkeley, CA, USA

\subsection{6/oemed-2014-102362.122}

Objectives To evaluate solvent exposures of automotive repair workers and investigate associated neurologic and reproductive effects.

Method Industrial hygienists conducted site-visits, air measurements, and interviews to prepare questions about task frequency, work practices, and products. Participants were recruited from IAMAW. Clinical exams evaluated peripheral neuropathy, neurocognition, colour discrimination, time to pregnancy, and urinary reproductive hormonal metabolites.

Results The 835 participants examined at the BASS clinic had worked over 3000 jobs at 1952 shops. Algorithms were developed to estimate individual solvent exposures in each year by integrating self-reported task frequency with MSDSs, measured and modelled airborne concentrations and dermal absorption. Major temporal changes occurred in source of exposures, e.g., solvent tanks accounted for $71 \%$ of solvent exposures in the 1960 s, $30 \%$ in $2000-04$, but only $7 \%$ in $2005-2012$; concomitantly, exposures from aerosol cans rose from $23 \%$ to $64 \%$ then $84 \%$, while composition changed dramatically, notably for hexane and perchloroethylene. Hexane was not used prior to 1989 and was eliminated from most products after 2000, when peripheral neuropathy was reported among automechanics. 52\% of the automechanics were exposed to hexane for a mean of 5.3 (0.1-12) years, and $80 \%$ of these had concomitant exposure to acetone, which potentiates neurologic effects of hexane in rodents. Cumulative hexane exposures were low: mean $=78.1$ $\mathrm{mg} / \mathrm{m}^{3}$ years $\left(\mathrm{TLV}=176 \mathrm{mg} / \mathrm{m}^{3}\right)$.

Conclusions Work histories were more complex than indicated in the pilot of 39 mechanics. Exposures were significantly affected by temporal trends in cleaning methods, composition of materials, and work practices. Epidemiologic studies must account for these changes. 